\title{
Correlation between Psychometric Tests and Mismatch Negativity in Preschool Children
}

\author{
Patricia Bauer Martin Burger Peter Kummer Joerg Lohscheller \\ Ullrich Eysholdt Michael Doellinger \\ Department of Phoniatrics and Pediatric Audiology, University Hospital Erlangen, Erlangen, Germany
}

\section{Key Words}

Mismatch negativity · Auditory event-related potential •

Preschool children $\cdot$ Central auditory processing disorder

\begin{abstract}
The objective was to determine whether mismatch negativity (MMN) is suitable to supplement subjective psychometric subtests of central hearing. We assessed 13 healthy children and 32 children with central auditory processing disorder (CAPD). Three different types of sound deviants were presented in a multi-deviant MMN design. At group level, the incidence of MMN was always higher in clinically diagnosed controls. Children with better results in the subtest Auditory Memory Span had a higher incidence of MMN. The controls also had peak latencies that occurred significantly earlier in frontal, central and temporal electrode sites. The area under the curve (AUC) displayed an asymmetric distribution in CAPD children, who tended to have a left-hemispheric dominance. AUC, peak latency, and the incidence of MMN reflected the discriminative ability of CAPD children. Hence, these characteristics could be used for investigating children with deficits in central hearing and can supplement psychometric tests.

Copyright $\odot 2009$ S. Karger AG, Basel
\end{abstract}

\section{Introduction}

Central auditory processing disorder (CAPD) is an umbrella term for several problems interfering with the processing of auditory information in the brain. Its cause is not an impairment of peripheral hearing but genetic factors, delayed or interfered maturation of the brain, environmental agents, or insufficient offers to learn $[1,2]$. The American Speech-Language-Hearing Association [3] defined the mechanisms that can be characteristically affected in patients with CAPD: 'sound localization and lateralization, auditory discrimination, auditory pattern recognition, temporal aspects of audition [...], auditory performance in competing acoustic signals [...] and auditory performance with degraded acoustic signals'.

Identifying children with CAPD is important since adequate processing of acoustic information is critical for speech and language development [4]. There is a profoundly negative influence of central auditory deficits on language development like specific language impairment (SLI), communication disorders or reading disorders: children with SLI struggle to identify short sounds followed by noise [6]. They need significantly more time than normal children to process auditory stimuli $[7,8]$.

\section{KARGER}

Fax +4161306 1234 E-Mail karger@karger.ch www.karger.com
Michael Doellinger

Department of Phoniatrics and Pediatric Audiology, University Hospital Erlangen Bohlenplatz 21, DE-91054 Erlangen (Germany)

Tel. +49 913185 33815, Fax +49 91318539272

E-Mail michael.doellinger@uk-erlangen.de 
The contribution of single components of impaired central auditory performance in children with SLI is still unclear though $[9,10]$. One of the probable reasons for this issue is due to the methods of testing. Traditionally, audiologically based psychometric language tests are used for the assessment of CAPD. However, such psychometric tests depend on motivation, attention, memory [11], and intelligence. Furthermore, there are not only cognitive but also linguistic factors involved in the tests $[12,13]$. Moreover, these tests depend on examiner experience and patient compliance, which is highly problematic in children [9]. Additionally, not all tests are standardized, and their quality and validity may be debatable [1]. Therefore it is recommended to conduct several tests in order to obtain a diagnosis [14]. Hence, over the past few years psychometric test batteries have been developed that can lead to a reliable diagnosis $[1,14]$. The main interest today, though, rests on more objective tests like electroencephalography (EEG) and auditory event-related potentials (AEPs).

In this study, we examined auditory evoked mismatch negativity (MMN) that was first described by Näätänen et al. [23] in 1978. It enables objective measurement of auditory discrimination ability [15], which is one of the factors assumed to be negatively affected in children with CAPD [3]. Therefore it seems to be a very promising tool for investigating CAPD [16-22].

MMN is an AEP component that occurs when a different stimulus is presented to a subject in a train of identical auditory stimuli [23]. It is interpreted as the outcome of a comparison process between the deviant stimulus and a memory trace left behind from a repetition of the standard stimulus [24]. It can be quantified by subtracting the EEG responses to the standard stimulus from those to the deviant stimulus. The use of MMN has several advantages. Eliciting MMN by tone stimuli is a nonverbal examination (it can also be derived using speech tasks, e.g. minimal pair syllables) and moreover, it is an objective measurement and does not require active participation on the part of the subject. However, there are also disadvantages concerning the MMN, e.g. that it is time-consuming. The stimulus ratios $(1: 7-1: 10)$ used in earlier studies [25-27] are not acceptable for clinical use. Furthermore, there is a need for trained experts that can analyze the data visually, which in turn is very subjective.

Up to now, several studies have shown that heterogeneous groups of children with developmental disturbances display changes in MMNs suggesting delayed central auditory processing. For example, Korpilahti [20],
Korpilahti and Lang [28] and Holopainen et al. [18] found attenuated amplitudes of MMN using frequency deviants in children with SLI. Lachmann et al. [29] examined children with impairment of frequent-word reading who tended to have diminished MMNs as well. Moreover, in another study, dyslexic children were found to have smaller MMN in response to frequency deviants compared to their controls [30, 31]. In a study by Kraus et al. [32], children with poor discrimination abilities for rapid acoustic changes that occur in speech (dalpha/galpha) also had significantly lower amplitudes and smaller areas under the curve (AUCs) of MMN than healthy controls.

However, examinations with MMN have produced contrasting results. For example, Alonso-Búa et al. [5] found no difference concerning MMN characteristics between children with reading difficulties and their controls. Dyslexic Chinese schoolchildren tested by Meng et al. [33] did not differ in MMN characteristics from healthy children. Sharma et al. [15] as well as Schulte-Körne et al. [34] found disordered children did not differ from healthy children regarding reading abilities. Uwer et al. [35] found attenuated MMN waves in SLI children in response to speech stimuli but no different MMN waveforms in response to tones.

The studies mentioned earlier, however, indicate that disorders in the auditory perception affect MMN. To transfer MMN recordings to clinical practice, the promising results gained at group level have to confirm selectivity about individual subjects.

Thus, the aim of the present study was to examine whether individual performance in auditory functions is reflected in MMN. This means we were interested in physical aspects of perception like frequency and intensity, and temporal aspects of audition like gap detection reflected in MMN. For this purpose, the outcomes of psychometric language and hearing tests were analyzed for correlations with MMN characteristics derived in a multi-deviant design of tone stimuli. Besides a control group of normal-hearing children, CAPD children with diminished auditory performance participated in this study.

\section{Methods}

Subjects

Forty-five German-speaking preschool children (24 males, 21 females; mean age 6 years, range 5-7 years) participated in the study. Informed consent was obtained from the parents of all children. Based on preschool screenings at the Public Health Department of Erlangen (Germany), 41 children (20 male, 21 female) 
were suspected to have speech disorders. Subsequently, they were examined in more detail at the University Department of Phoniatrics and Pediatric Audiology (Erlangen). Figure 1 gives an overview of the test battery that was administered.

Case histories were conducted for each child. Pure-tone audiometric testing indicated normal hearing for all participating children. The children were tested with the Culture Fair Intelligence Test 1 [36]. Nine children were excluded because of psychoneurological problems (IQ <85). The remaining 32 children had an intelligence quotient ranging from 85 to 130 (mean IQ 104).

The following German psychometric tests were conducted: Heidelberger Test of Language Development (HSET) [37], Heidelberger Preschool Screening (HVS) [38, 39], Psycholinguistic Analysis of Infantile Speech Disorders [40], Bielefelder Screening for Early Diagnosis of Reading and Writing Disorders, Active Vocabulary Test, and Göttinger Speech Perception Test II [41], which includes hearing in a noisy environment. These tests include various analyses that are widely used in psychometric tests in every language. CAPD was diagnosed according to test thresholds and after clinical examination by experienced phoniatricians. Thirtytwo children were thus diagnosed with CAPD.

Thirteen healthy children from public preschools served as the control group (referred to as 'controls'). None of the remaining 45 children ( 13 controls +32 CAPD children) had been identified as having serious emotional disturbances or mental retardation. Finally, AEPs were conducted on all remaining 45 children.

\section{Behavioral Tests}

The subtests of HVS and HSET were analyzed in more detail in this study. The results of these subtests are presented as T values (mean value 50 , standard deviation 10 ) $[37,38]$. T values $>40$ are the criterion for passing a subtest according to the test manuals. Each time comparisons with the single subtests were made, the children were divided into two groups for each subtest according to the threshold $\mathrm{T}$ value of 40 . Group sizes were variable in each allocation.

Heidelberger Test of Language Development

The HSET is a psychometric test consisting of nine subtests assessing the developmental status of linguistic abilities. Three of the most widely used subtests in Germany were administered in this study:

- Comprehension of Grammatical Structures tests the ability to understand subject-object differentiations: the child has to imitate spoken sentences nonverbally with wooden toy animals.

- Imitation of Grammatical Structures challenges the linguistic reproduction of spoken sentences. The level of difficulty is determined by the use of verbs in the active and the passive voice and in different tenses. Inability to imitate grammatically difficult sentences suggests a lack of familiarity with these specific grammatical structures. Moreover, it proves the memorization and the reproduction of different complex contents of speech to evaluate one aspect of auditory memorization.

- Item Classification examines the aspect of concepts in speech as well as levels of linguistic structure. In this subtest, a child has to choose one out of 30 picture cards corresponding to a certain category (e.g. animals).

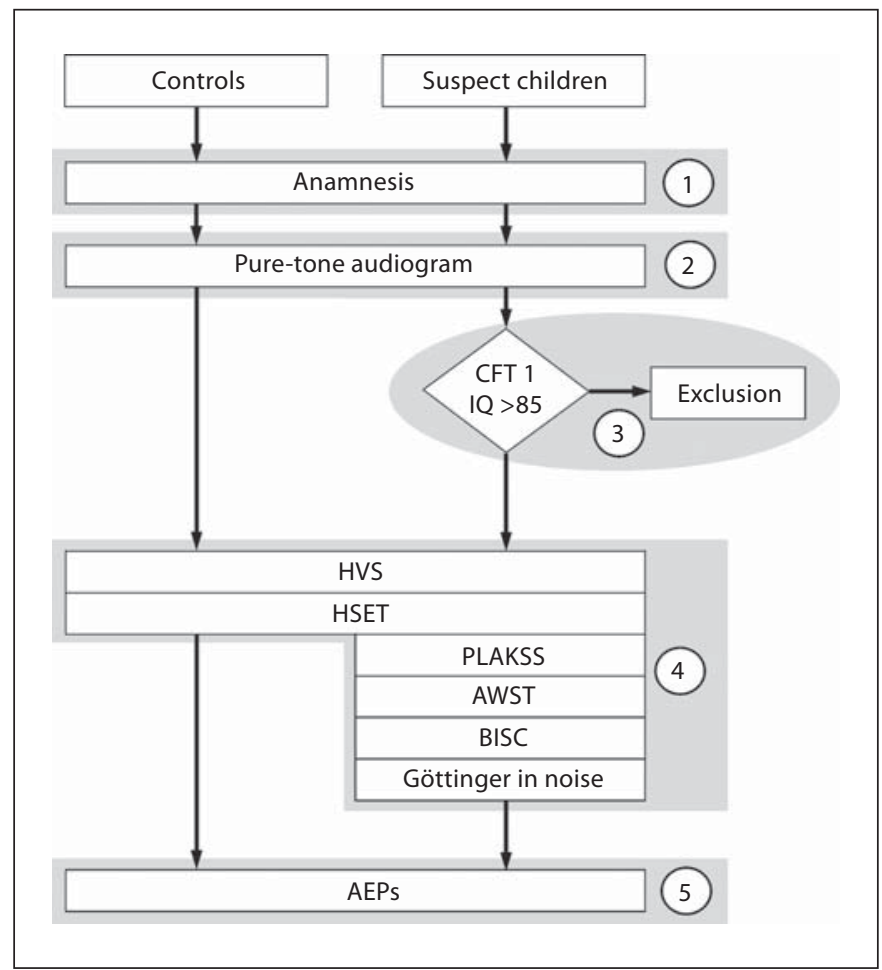

Fig. 1. Test battery for CAPD. CFT $1=$ Culture Fair Intelligence Test 1; PLAKSS = Psycholinguistic Analysis of Infantile Speech Disorders; AWST = Active Vocabulary Test; BISC = Bielefelder Screening for Early Diagnosis of Reading and Writing Disorders.

Heidelberger Preschool Screening

The HVS measures a subject's state of auditory-kinesthetic perception and abilities of speech processing. It is subdivided into 12 subtests; the following seven subtests were administered in this study:

- Auditory Memory Span identifies the range of the working memory: the child has to reproduce a presented series of numbers. The test starts with two numbers and goes up to six numbers in-line.

- Initial Sound Analysis tests specific phonological awareness by examining the ability to use small linguistic items. A child has to name the first letter (consonant or vowel) occurring in a word.

- Syllable Segmentation challenges a child to break down larger sound items by clapping the syllables of a word, i.e., marking word boundaries. Thus, phonological awareness in general is tested.

- Phoneme Discrimination detects the ability to discriminate phonemes that sound alike. A child has to decide whether or not two similar sounding words are actually the same.

- Motor Activity of Articulation tests the conversion of phonological information into articulation programs. During the first part of the subtest, the child has to repeat tongue twisters containing diadochokinetic patterns of articulation (e.g. ka- 
ta-ka ka-ta-ka). In the second part, words with different patterns of articulation or clusters of consonants have to be reproduced (i.e., nonsense words like te-ki-pu).

- Recognizing Rhyming Words consist of word pairs that are presented to the child. The child has to decide whether they sound similar or not. This task is designed to test a child's ability to detect constant speech segments so that he/she will later be able to convert sound into spelling.

- Word Families examines the ability to handle morphemes by presenting four words to a child. He/she has to choose the ones belonging to the same word family [39] and eliminate the one word that does not fit.

\section{Electrophysiological Examination}

EEG Recording and Averaging

The recordings were conducted in a soundproof, electrically shielded chamber via two loudspeakers. The children were told to concentrate on a displayed movie without sound and to ignore the stimuli presented. To insure the vigilance of the children, a monitoring TV camera was mounted in the recording room [42]. The continuous EEG was recorded at a sampling rate of $500 \mathrm{~Hz}$ with the BrainVision Recorder 1.01 (Brain Products GmbH, Gilching, Germany) and analyzed with the program BrainVision Analyzer 1.04 (BrainProducts $\mathrm{GmbH}$ ) using $19 \mathrm{Ag} / \mathrm{AgCl}$ electrodes (Fpl, Fp2, Fz, Cz, Pz, F7, F3, F4, F8, C3, C4, T7, P3, P4, T8, T3, T4, O1, O2) placed according to the international 10-20 system [43]. The impedance of each electrode was less than $10 \mathrm{k} \Omega(80 \%$ less than $2 \mathrm{k} \Omega, 95 \%$ less than $5 \mathrm{k} \Omega$ ). While recording, a ground electrode on the vertex $(\mathrm{FCz})$ served as reference. Two additional electrodes (TP1, TP2) over each mastoid were used as reference electrodes offline and another electrode below the right eye served as a control for artificial eye movements. Sweeps with EEG recordings exceeding $\pm 150 \mu \mathrm{V}$ were rejected as artifacts [29]. The raw data was band pass-filtered offline with a low-frequency cutoff of 0.13 $\mathrm{Hz}$ and a high-frequency cutoff of $20 \mathrm{~Hz}$ with a slope of $12 \mathrm{~dB} / \mathrm{oc}-$ tave. The mean voltage of the prestimulus interval of $50 \mathrm{~ms}$ served as a baseline.

MMN Paradigm: Stimuli and Procedure

Four different stimuli were used: (1) standard stimulus (SS), a harmonic stimulus consisting of three sinusoidal components $(500,1,000$ and $1,500 \mathrm{~Hz})$ with a duration of $100 \mathrm{~ms}$ at $67 \mathrm{~dB}$ including a 5 -ms rise and fall; (2) frequency deviant (FD) with a $10 \%$ higher frequency $(550,1,100$ and 1,650 Hz) than SS; (3) intensity deviant (ID) at $77 \mathrm{~dB}$ instead of $67 \mathrm{~dB}$, and (4) gap deviant (GD) containing a $16-\mathrm{ms}$ gap with a $5-\mathrm{ms}$ rise and fall in the middle of an SS.

The two stimuli 'direction' and 'duration', as used by Näätänen et al. [25], were not used in this study. Preliminary studies indicated that the contrast between the duration deviant and SS was inappropriate. This left three deviant types to work with.

The stimuli were presented with the Brain Amp MR (Brain Products $\mathrm{GmbH}$ ). A new MMN paradigm in pseudorandomized order (fixed interstimulus interval of $500 \mathrm{~ms}$ ) slightly different from the latest 5-deviant paradigm [25] was used. Two standards were followed by one randomly chosen deviant (2:1) [44]. Because of the significant drop in MMN magnitude after the first $10 \mathrm{~min}$ of measuring [45], the recordings were conducted 3 times placing breaks of 5 min between them. Three identical recorded sequences of 5 min were obtained consisting of a total of 1,008 standard signals and 378 deviant signals (126 for each single deviant). The continuous dataset was segmented in sweeps of $550 \mathrm{~ms}$ consisting of a time interval of -50 to $500 \mathrm{~ms}$ according to stimulus onset. After rejecting the artifacts, the AEPs were computed by averaging the remaining responses separately for each stimulus type (SS, FD, ID, and GD). There was a mean of 897 ( \pm 176$)$ sweeps that were averaged for the standard signal as well as a mean of 108 ( \pm 21$)$ sweeps for each deviant. The difference waveform containing the MMN was gained by subtracting AEPs evoked by the standard stimuli from those elicited by the deviant stimuli.

\section{Data Analysis}

Extracting MMN Characteristics

The commonly investigated MMN characteristics peak amplitude, onset latency, peak latency, duration, and AUC were obtained $[15,46]$. A more objective statistical analysis than the usual approach of building a difference signal from standard and deviant AEP (and extracting all MMN characteristics out of this visually inspected grand average waveform) was conducted.

Using the sweeps provoked by standard and deviant stimuli for every recorded point $\left(t_{0}-t_{250}\right)$ of the 500 -ms post-stimulus interval, a one-tailed t test comparing the mean value of the deviant to the mean value of the standard was conducted, yielding 251 tests. To reduce the statistical alpha error in response to this multitude of tests, a logical AND-operation of an $\mathrm{H}_{1}$ hypothesis (mean values of deviant and standard sweeps are different) in the two electrode sites $\mathrm{Fz}$ and $\mathrm{Cz}$ was applied. These are the electrode sites where the largest MMN responses were found. A subject was assumed to offer an MMN if paired t tests showed a significant difference ( $\mathrm{p} \leq 0.05)$ in mean values between standard sweeps and deviant sweeps for at least $20 \mathrm{~ms}$ simultaneously on both channels [45]. The PC software used for calculations was MAT$\mathrm{LAB}$ version 6.5 .

The two characteristics onset latency and duration were calculated once during the $\mathrm{H}_{1}$ signal.

(1) Onset latency: first sample of $\mathrm{H}_{1}$ signal unequal to zero.

(2) Duration: length of $\mathrm{H}_{1}$ signal ( $\geq 20 \mathrm{~ms}$ ).

The characteristics peak amplitude and peak latency as well as AUC were calculated separately for each of the 19 electrode sites. The time interval of the $\mathrm{H}_{1}$ signal gained from electrode sites $\mathrm{Fz}$ and $\mathrm{Cz}$ was used for the extraction of peak amplitude, peak latency and AUC.

(3) Peak amplitude: the most negative voltage according to the $\mathrm{H}_{1}$ signal was calculated at all 19 electrode sites.

(4) Peak latency: time point according to peak amplitude in all 19 electrode sites.

(5) AUC: area under the negative curve of evident MMN during $\mathrm{H}_{1}$ signal was integrated at all 19 electrode sites.

If several significant time intervals were divided by a nonsignificant interval, the duration was calculated as the sum of both intervals. The amplitude was set at the most negative voltage in all intervals and the AUC was calculated as the sum of all integrated areas of the two time intervals.

Based on the comparison of mean values for standard and deviant sweeps, one significant difference time window of SS and each deviant was obtained ranging from 140-500 ms for FD, GD and ID. For further calculations $140 \mathrm{~ms}$ was used as the beginning time point for all deviants. A cutoff point at $400 \mathrm{~ms}$ was set for each time interval to exclude late MMN (also referred to as late discriminative negativity, LDN) from the following cal- 
Table 1. HSET and HVS test results for controls (C) and CAPD children (S) with mean value (mean), minimum value (min) and maximum value $(\max )$

\begin{tabular}{|c|c|c|c|c|c|c|c|c|c|}
\hline & & \multicolumn{2}{|l|}{$\mathrm{T}_{\text {value }}{ }^{1}$} & \multicolumn{2}{|c|}{ Min T value } & \multicolumn{2}{|c|}{ Max T value } & \multicolumn{2}{|c|}{ Failure rate, \% } \\
\hline & & $\mathrm{C}$ & $S$ & $\mathrm{C}$ & S & $\mathrm{C}$ & $S$ & $\mathrm{C}$ & S \\
\hline \multirow[t]{3}{*}{ HSET } & CS & $47.4(12.4)$ & $42.5(7.8)$ & 30 & 30 & 68 & 63 & 23.1 & 37.5 \\
\hline & IS & $49.3(6.6)$ & $42.4(6.7)$ & 38 & 28 & 57 & 57 & 7.7 & 25.0 \\
\hline & IC & $48.9(12.9)$ & $47.9(11.2)$ & 24 & 30 & 68 & 65 & 15.4 & 21.9 \\
\hline \multirow[t]{7}{*}{ HVS } & AMS & $51.4(5.7)$ & $40.4(9.2)$ & 41 & 23 & 60 & 65 & 0.0 & 43.8 \\
\hline & ISA & $53.8(8.6)$ & $45.4(12.8)$ & 41 & 20 & 64 & 63 & 0.0 & 25.0 \\
\hline & SYS & $59.0(4.8)$ & $52.8(8.4)$ & 48 & 36 & 63 & 63 & 0.0 & 12.5 \\
\hline & $\mathrm{PD}$ & $53.1(8.8)$ & $39.9(6.3)$ & 40 & 25 & 66 & 58 & 0.0 & 46.9 \\
\hline & MAA & $49.3(8.3)$ & $38.2(8.9)$ & 37 & 20 & 65 & 61 & 7.7 & 56.3 \\
\hline & RRW & $52.4(5.9)$ & $50.1(6.8)$ & 42 & 35 & 58 & 58 & 0.0 & 3.1 \\
\hline & $\mathrm{WF}$ & $51.6(5.6)$ & $43.6(9.6)$ & 45 & 20 & 63 & 62 & 0.0 & 25.0 \\
\hline
\end{tabular}

Percentage of failure rate of controls and CAPD children in psychometric tests (\%). CS = Comprehension of Grammatical Structures; IS = Imitation of Grammatical Structures; IC = Item Classification; AMS = Auditory Memory Span; ISA = Initial Sound Analysis; $\mathrm{SYS}$ = Syllable Segmentation; PD = Phoneme Discrimination; MAA = Motor Activity of Articulation; RRW = Recognizing Rhyming Words; WF = Word Families.

${ }^{1}$ Data shown as mean with SD in parentheses.

culations [29]. This second negative wave can be observed at 400-500 ms in children [5]. It was first described by Korpilahti et al. [47] in 1995 who found a late negativity appearing at 432 $( \pm 30) \mathrm{ms}$. It does not seem to be as stable as the MMN [48]; there are similarities to the MMN like the appearance under the same stimulus conditions in predominantly frontal regions, but in contrast, LDN diminishes in amplitude with age unlike the developmental stability of MMN [49]. Additionally, LDN does not consistently change in response to stimulus variation and thus does not appear to be directly linked with sensory sound discrimination [26].

\section{Statistical Analyses}

(1) Two-way ANOVAs were conducted to test the effect of group (two levels: control, CAPD child) and deviant type (three levels: frequency, intensity, and gap detection) for each MMN characteristic and electrode site.

(2) Topographic analyses between corresponding hemispheric electrode sites were examined with paired t tests.

(3) The incidence of MMN (0-3) in a child was examined between the control group and CAPD children (percentage distribution and t tests).

(4) The influence of age, intelligence (bivariate correlations using the Spearman correlation coefficient) and gender (ANOVA) were investigated.

For all tests a $\mathrm{p}$ value of $\leq 0.05$ was accepted as statistically significant. Post-hoc analyses were conducted with a StudentNewman-Keuls test (PC software SPSS 14.0 for Windows, SPSS Inc., 2006, Chicago, Ill., USA).

\section{Results}

\section{Descriptive Statistics of Psychometric Subtests}

The abilities of the majority of children are all distributed at higher $\mathrm{T}$ values. The mean average of both groups was above the threshold of T value 40 . However, the control group was significantly better than the CAPD group in all subtests $(\mathrm{F}=6.5$; $\mathrm{p}<0.01$; table 1$)$.

Thirteen of the 45 children were below the threshold $T$ value of 40 in one subtest (below one standard deviation according to the test manual) and 25 children were below a $\mathrm{T}$ value of 40 in more than one subtest. The remaining 7 children had $\mathrm{T}$ values above 40 in all subtests.

\section{Quality and Quantity of MMN}

Standard and deviant waveforms for the controls and CAPD children are displayed in figure 2. The waveforms of both groups were separately averaged on channel Fz. A prominent negativity in the difference waveforms was observed at 140-400 ms (MMN) (fig. 3). LDN values between 400 and $500 \mathrm{~ms}$ were excluded as described in the section Behavioral Tests.

All grand average waveforms display prominent $\mathrm{P} 1$ and N2 (fig. 2). The latency of P1 is at $100 \mathrm{~ms}$, its amplitude reaching a mean of $8 \mu \mathrm{V}$. The $\mathrm{N} 2$ can be found at 250 
Table 2. Mean values of MMN characteristics in CAPD children and controls

\begin{tabular}{|c|c|c|c|c|c|c|c|c|c|c|c|c|c|c|c|}
\hline & \multicolumn{15}{|c|}{ MMN characteristics } \\
\hline & \multicolumn{3}{|l|}{$\mathrm{OL}$} & \multicolumn{3}{|l|}{ PL } & \multicolumn{3}{|l|}{ PA } & \multicolumn{3}{|l|}{ AUC } & \multicolumn{3}{|c|}{ duration } \\
\hline & GD & FD & ID & GD & FD & ID & GD & FD & ID & GD & FD & ID & GD & FD & ID \\
\hline $\mathrm{C}$ & 220.20 & 215.50 & 244.80 & 332.00 & 290.00 & 343.78 & -8.57 & -10.47 & -10.25 & -766.11 & $-1,101.06$ & -860.41 & 124.00 & 70.00 & 99.00 \\
\hline$S$ & 213.09 & 179.23 & 261.76 & 365.65 & 309.81 & 331.71 & -10.38 & -10.79 & -10.89 & $-1,178.61$ & $-1,285.98$ & $-1,200.76$ & 128.67 & 70.77 & 124.59 \\
\hline
\end{tabular}

$\mathrm{OL}=$ Onset latency; PL = peak latency; PA = peak amplitude. PL, PA and AUC only at electrode site Fz.
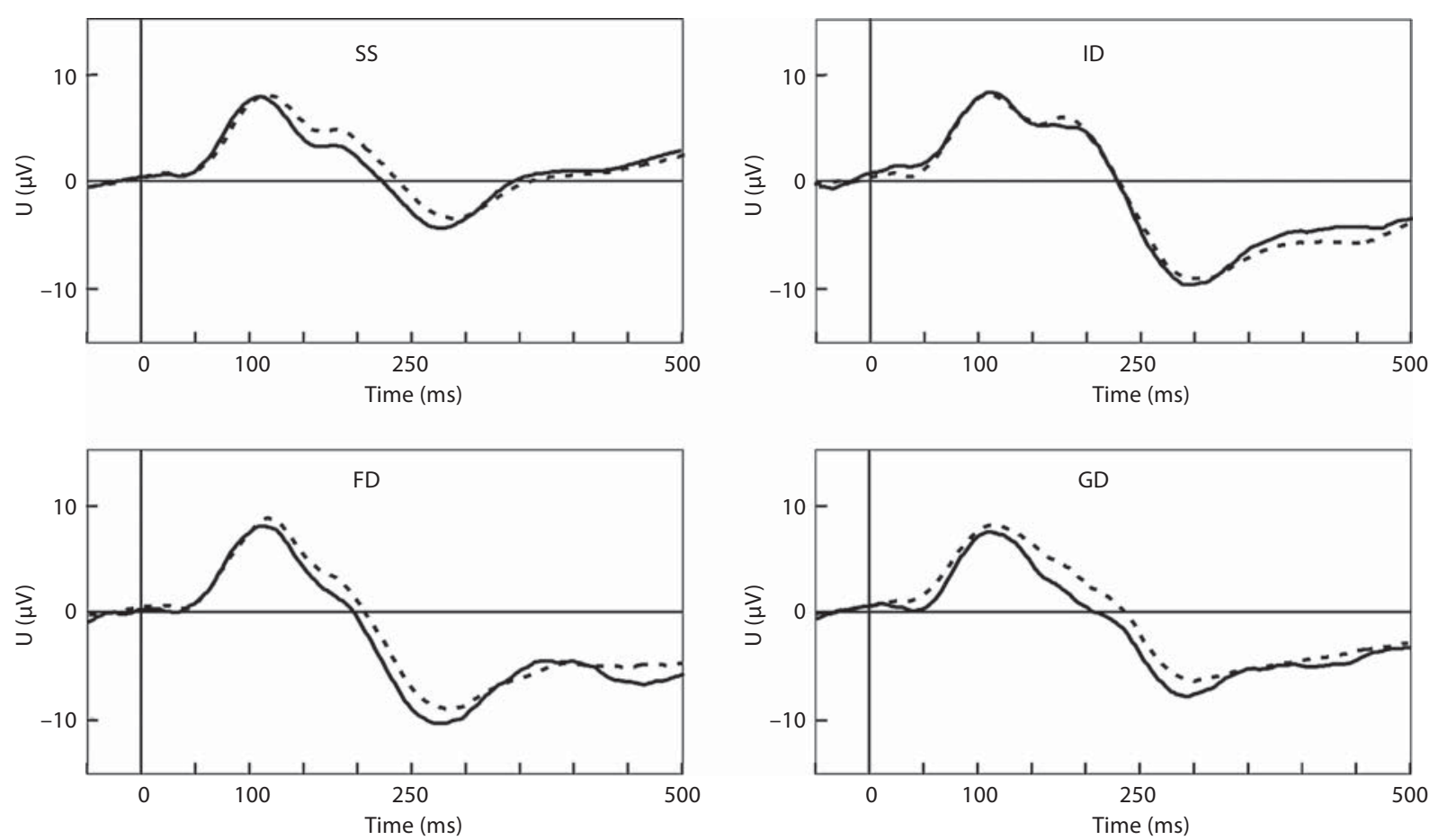

Fig. 2. Grand average waveforms of controls (continuous line) and CAPD children (dashed line) for SS and deviants (FD, ID, and GD).

ms with amplitudes of $-10 \mu \mathrm{V}$. However, $\mathrm{N} 2$ is more negative in the deviant waveforms (FD, ID, and GD) than in the standard waveform (SS). This amplitude difference is used to elicit the MMN. At group level, there are no differences between the grand average waveforms of the MMN. Table 2 shows the mean values of the MMN characteristics at group level.

Dependencies between the three deviants (FD, GD, ID) were analyzed using ANOVA (MMN characteristics).
The characteristic peak latency of FD occurs significantly earlier $(\mathrm{p}<0.05)$ than the peak latencies of ID or GD at electrode sites Fp1 $(\mathrm{F}=7.7 ; \mathrm{p}=0.001), \mathrm{Fp} 2(\mathrm{~F}=8.7 ; \mathrm{p}=$ 0.003), F3 ( $\mathrm{F}=7.9 ; \mathrm{p}=0.001), \mathrm{F} 4(\mathrm{~F}=6.7 ; \mathrm{p}=0.002), \mathrm{C} 3$ $(\mathrm{F}=8.4 ; \mathrm{p}=0.0004), \mathrm{C} 4(\mathrm{~F}=3.6 ; \mathrm{p}=0.032), \mathrm{F} 8(\mathrm{~F}=5.6$; $\mathrm{p}=0.005), \mathrm{T} 4 \quad(\mathrm{~F}=6.9 ; \mathrm{p}=0.002), \mathrm{Fz}(\mathrm{F}=6.4 ;$ $\mathrm{p}=0.003), \mathrm{Cz}(\mathrm{F}=5.2 ; \mathrm{p}=0.007)$, and $\mathrm{Pz}(\mathrm{F}=3.5 ; \mathrm{p}=$ 0.035; fig. 3 ). 
Table 3. Quantity (\%) of MMN in CAPD children $(\mathrm{n}=32)$ and controls $(\mathrm{n}=13)$

\begin{tabular}{lll}
\hline MMN detected, $\mathrm{n}$ & CAPD, \% & Controls, \% \\
\hline 0 & 15.6 & 0 \\
1 & 12.5 & 7.7 \\
2 & 21.9 & 23.1 \\
3 & 50 & 69.2 \\
\hline
\end{tabular}

Table 4. MMN (\%) in response to single deviant stimuli in children

\begin{tabular}{lll}
\hline & Controls & CAPD \\
\hline FD & 69.2 & 65.6 \\
ID & 69.2 & 59.4 \\
GD & 76.9 & 53.1 \\
\hline
\end{tabular}

GD, FD, and ID have similar peak latencies: 197, 205, and $207 \mathrm{~ms}$. Amplitudes reach on average $-3.9 \mu \mathrm{V}(\mathrm{GD})$, $-4.7 \mu \mathrm{V}$ (ID), and $-5.5 \mu \mathrm{V}$ (FD). Onset latencies are 149 $\mathrm{ms}$ (ID), $150 \mathrm{~ms}$ (FD), and $158 \mathrm{~ms}(\mathrm{GD})$. The AUCs of the negative waveform are $-361 \mathrm{~ms} \times \mu \mathrm{V}(\mathrm{GD}),-510 \mathrm{~ms} \times$ $\mu \mathrm{V}$ (ID), and $520 \mathrm{~ms} \times \mu \mathrm{V}(\mathrm{FD})$.

Concerning the topographic scalp distribution of the MMN, no differences can be seen between CAPD children and controls (fig. 4).

Comparing the incidence of MMN overall as well as in response to each single deviant found in the two groups of children, the controls had a higher percentage of MMN as a result of the three deviants (tables 3,4$)$. In the time interval of $140-400 \mathrm{~ms}$, a significant $\mathrm{t}$ test $(\mathrm{p}=0.03)$ revealed a greater $\mathrm{MMN}$ incidence for the controls $\left(\right.$ mean $_{\text {controls }}=2.6 ;$ mean $\left._{\mathrm{CAPD}}=2.0\right)$.

\section{Comparing Psychometric Test Results with \\ MMN Characteristics}

(1) Two-Way ANOVA (MMNCharacteristics) for Group and Deviants. Controls had significantly smaller $(\mathrm{p}<$ 0.05) AUC at electrode sites Fp2 $(\mathrm{F}=4.4 ; \mathrm{p}=0.039)$, F8 $(\mathrm{F}=4.8 ; \mathrm{p}=0.03), \mathrm{T} 4(\mathrm{~F}=5.3 ; \mathrm{p}=0.024)$, and $\mathrm{T} 8(\mathrm{~F}=5.0$; $\mathrm{p}=0.029$ ). For further investigation we performed paired $t$ tests on laterally corresponding electrode sites. While the controls exhibited no hemispheric asymmetries, CAPD children had significant differences $(\mathrm{p}<0.05)$ between electrode sites Fp1 > Fp2, F7 > F8, T3 > T4, and T7

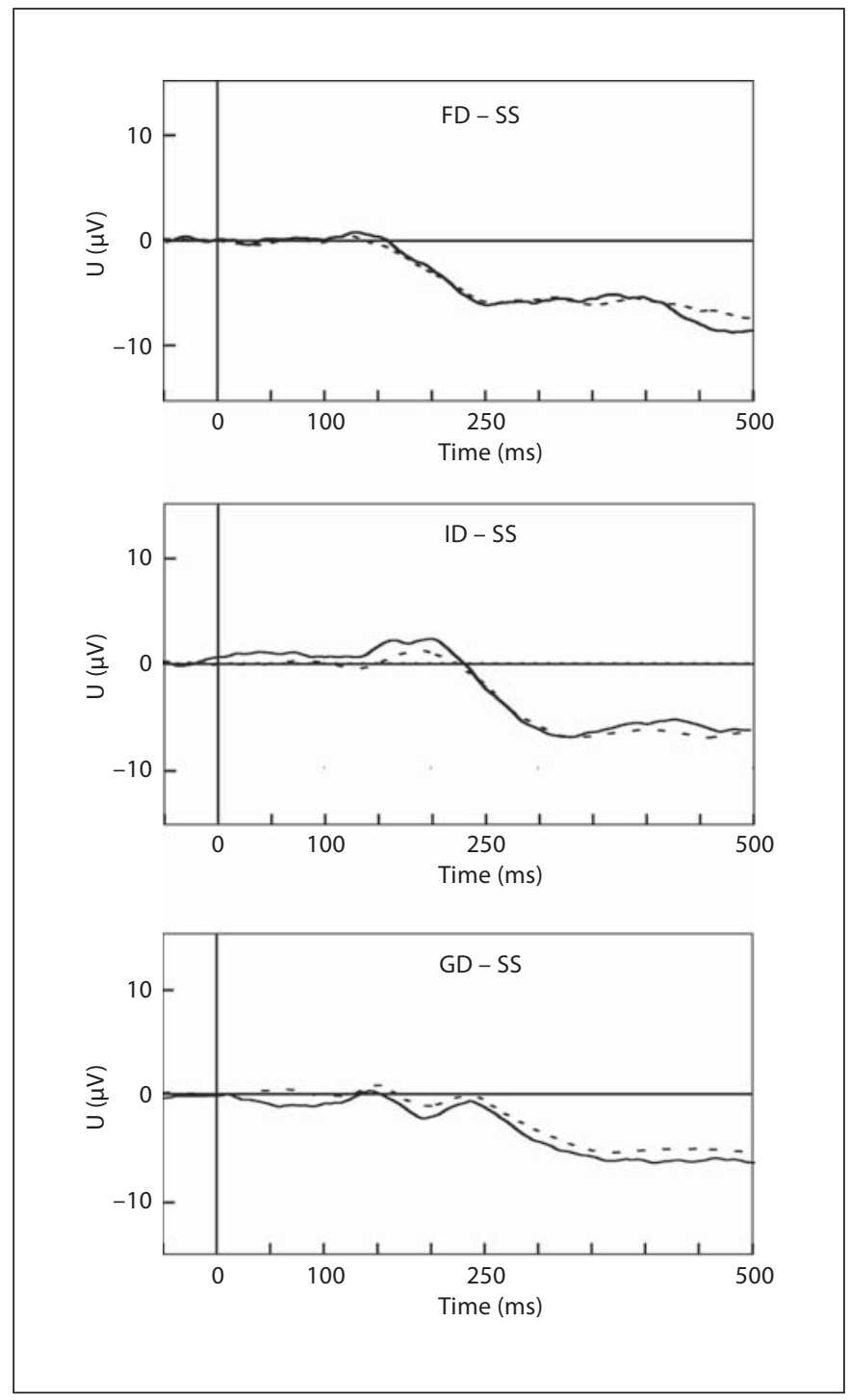

Fig. 3. Negative waveform containing MMN, calculated by subtraction (FD - SS, ID - SS, and GD - SS) at Fz.

$>$ T8. The AUC therefore is asymmetric in CAPD children; they tend to have left-hemispheric dominance. There were also group differences in electrode sites $\mathrm{F} 3$ $(\mathrm{F}=4.9 ; \mathrm{p}=0.03), \mathrm{F} 4(\mathrm{~F}=4.3 ; \mathrm{p}=0.042), \mathrm{C} 3(\mathrm{~F}=4.1 ;$ $\mathrm{p}=0.045), \mathrm{C} 4(\mathrm{~F}=4.6 ; \mathrm{p}=0.034), \mathrm{T} 3(\mathrm{~F}=8.2 ; \mathrm{p}=0.005)$, and $\mathrm{T} 4(\mathrm{~F}=7.8 ; \mathrm{p}=0.007)$. In controls, peak latencies occurred significantly earlier (fig. 5). Student-NewmanKeuls post-hoc analysis revealed no interaction with deviant types. The characteristics onset latency, duration and peak amplitude showed no significant differences in the two groups. 
Fig. 4. Scalp distribution of peak amplitudes at $\mathrm{Fz}$.

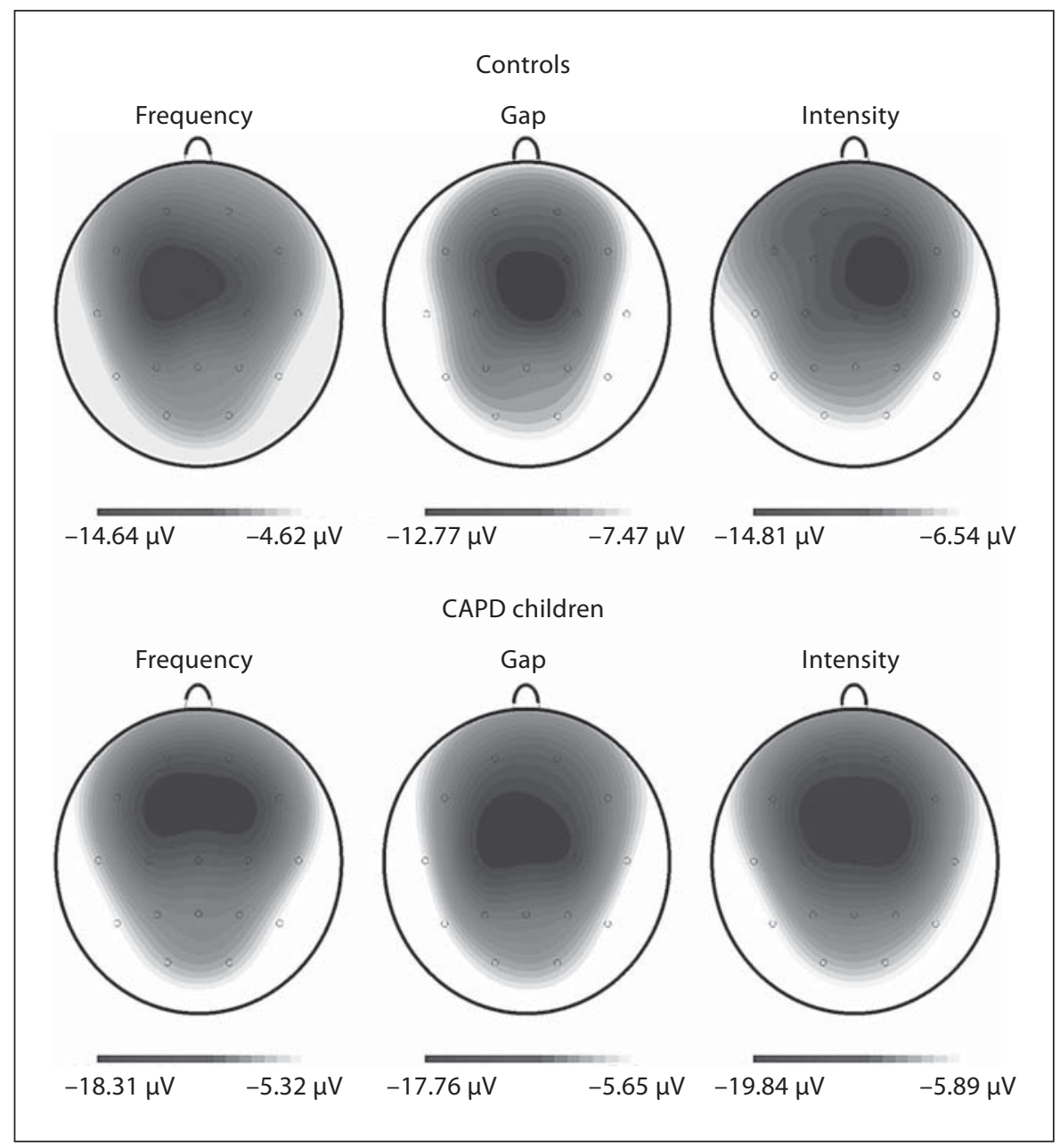

(2) T Tests [Single Subtests Separated in Two Groups (at T Value 40) $\times$ Incidence of $M M N]$. The general incidence of a MMN waveform (0-3) was compared with subtest results. There were differences between the two groups with $\mathrm{T}$ value $<40$ and $\mathrm{T}$ value $>40$ only in the Auditory Memory Span. In this subtest, children with a $\mathrm{T}$ value $<40$ had significantly less $\mathrm{MMN}(\mathrm{F}=6.5 ; \mathrm{p}=$ $0.028)$.

(3) Effect of Age/IQ/Gender on Subtests and MMN Characteristics. The variables age and IQ did not show any significant correlations with the subtest results as well as the parameter values of the MMN characteristics in bivariate correlations using the Spearman correlation coefficient. Gender also showed no significant results on the subtest results or on the parameter values of the MMN as proved by ANOVA (subtests/MMN characteristics).

\section{Discussion}

In the present study, MMN characteristics were obtained in response to changes in tone stimuli in CAPD children and controls. The objective was the examination of several extracted MMN characteristics and their interference in clinically diagnosed groups of controls and CAPD children and their psychometric test results. Since previous studies had shown changes in the MMN characteristics of children with developmental language disorders $[20,28,30,32]$, we investigated if children with a better outcome in psychometric tests also reveal 'better' MMN characteristics.

To avoid overlooking topographic relations, we investigated three (peak amplitude, peak latency, and AUC) out of five MMN characteristics (omitting onset latency and duration) for every channel with the risk of examining redundant data. Applying the updated paradigm [44], 


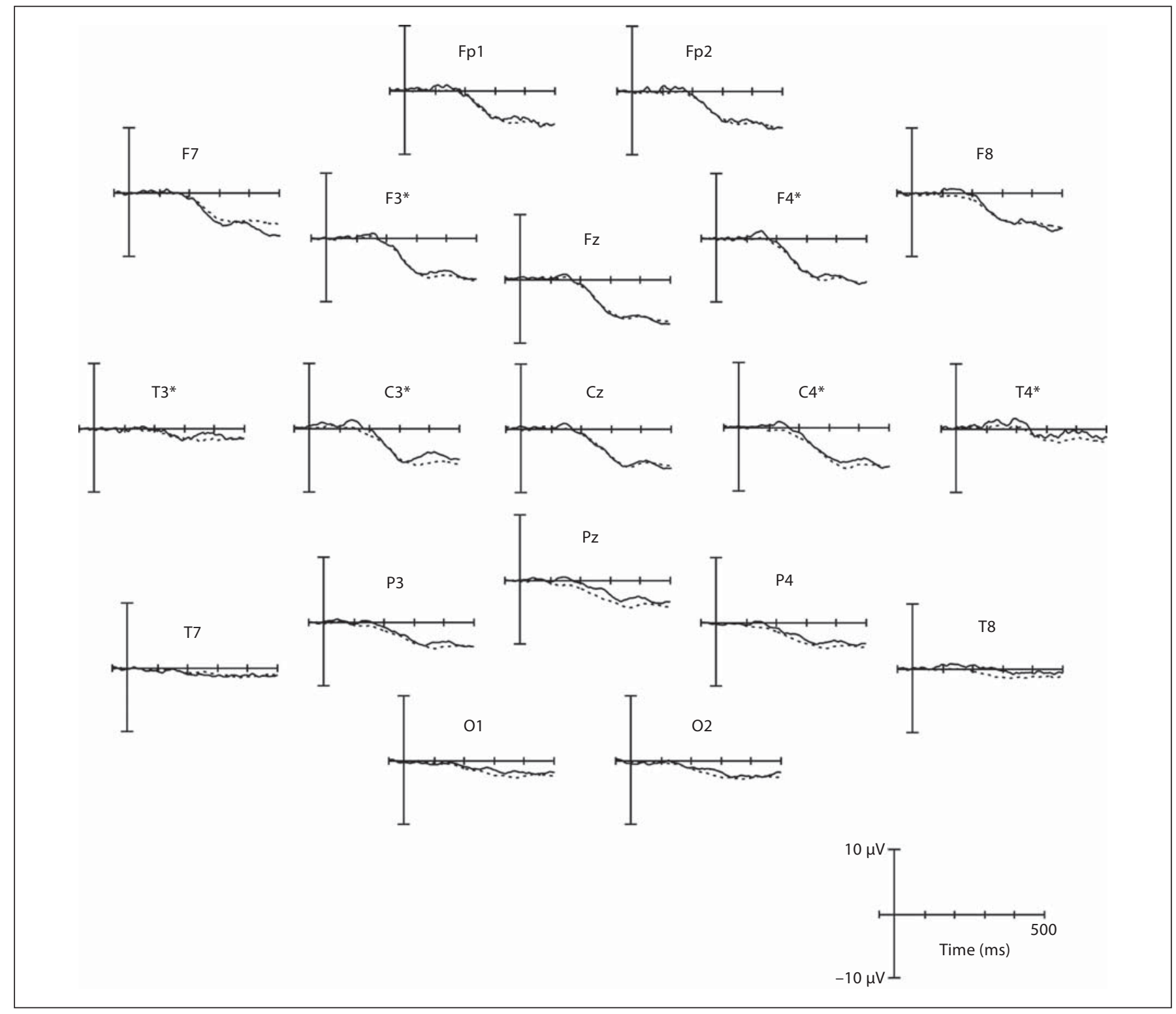

Fig. 5. Average peak latency in GD, FD, and ID at all electrode sites.

it only takes about $15 \mathrm{~min}$ (without breaks) to record the EEG data. The new paradigm was able to detect MMN in preschool children: comparing MMN values with other studies using different paradigms [51, 52], there are similar results. Further, using the introduced detection method via statistical analysis, only a few minutes are necessary to extract characteristics from the data.

We exclusively examined preschool children in a very limited age range of 5-7 years. This is in contrast to other studies, which chose a wide age range but neglected aspects of maturation [50].

\section{Psychometric Test Results}

The mean $T$ values obtained in the psychometric tests for both groups (controls/CAPD children) were always above 40. Controls had a mean T value of 51, CAPD children of 44. Most CAPD children had T values close to the threshold of $\mathrm{T}$ value 40 . This suggests that CAPD children are only slightly disordered in their perceptive abilities. Previous studies compared controls including children with minimal performance in their test results [29, 35 ] and therefore produced clear findings. Average children are removed from these investigations. In the pres- 
ent study, children clinically diagnosed with CAPD as well as children serving as controls were tested with a widely used German test battery. The difference between the two groups was significant $(\mathrm{p}<0.05)$ in all subtests. This suggests that these 10 audiologically oriented subtests are useful for examining CAPD.

\section{Mismatch Negativity}

The mean latency and amplitude of P1 at $100 \mathrm{~ms}$ were $+10 \mu \mathrm{V}$ (fig. 2), consistent with Čeponiené et al. [51] and Gomes et al. [52]. P1 always appeared around $100 \mathrm{~ms}$. Amplitudes from different studies are more difficult to compare: varying interstimulus intervals and frequencies can produce amplitudes from $\pm 1 \mu \mathrm{V}$ [53] up to $\pm 10 \mu \mathrm{V}$ [51].

The time interval where a significant negativity in the signal was found was $140-500 \mathrm{~ms}$. This is as expected, since Čeponiené et al. [27] noticed the MMN to start in preschool children around $150 \mathrm{~ms}$ and Alonso-Búa et al. [5] observed the beginning of LDN around $400 \mathrm{~ms}$. This is the end of the normal MMN waveform where we cut the time interval for calculations. The LDN is implied in the FD and ID, though it is blurred in the pictured grand average waveforms (fig. 2).

An MMN signal could be elicited in all controls but not in 5 CAPD children although psychometric tests suggested that they would be able to discriminate well [48] This result is consistent with Jansson-Verkasalo's [19] findings that not all children in her three combined studies displayed an MMN waveform.

\section{Controls versus CAPD Children}

Comparing the incidence of MMN at group level, there were always more MMN detected in the controls. This is consistent with the findings of Sharma et al. [15] that controls had more MMN than children with reading disorders (compensated and noncompensated) using tone stimuli.

Further, comparing the MMN characteristics, AUC and peak latency at group level, the values for controls were significantly different from those for CAPD children (smaller AUCs in the right hemisphere and generally earlier peak latencies). CAPD children tended to recognize less and show later perception of differing tones. This might indicate that CAPD children are in fact inferior discriminators.

Examining the AUC more closely, we found controls to have stable values over both hemispheres, whereas CAPD children had an asymmetric distribution of the AUC with a significant left-hemispheric dominance. This could mean that the perception of differing tones in
CAPD children takes place in laterally deviating areas of the brain.

In general, our results showed that psychometric tests correlate with specific MMN features. Although at group level some differences were found, further research is needed to determine the role of MMN in CAPD diagnostics.

The results of subtests as well as the characteristics of MMN were not influenced by other parameters that we measured in the children. Age, IQ, and gender did not affect the subtests or MMN characteristics. Holopainen et al. [18] also found no influence of age regarding groups of controls and dyslexics in MMN amplitude or peak latency, whereas Korpilahti $[20,28]$ found normal children to have a negative correlation between age and the onset latency of FD.

Finally, in this study we introduced an objective statistical method of extracting MMN [44] allowing reproducibility and objective comparison with future work.

Future research will have to analyze this statistical and objective method of extracting MMN characteristics more closely by extending it to more children and modifying age ranges. In addition, focusing on the incidence and peak latency of MMN in CAPD children will also be considered. Further, speech stimuli such as minimal pairs will be used in MMN examinations to develop and improve the new paradigm.

\section{Acknowledgments}

We would like to thank Mr. Eric Branda for proofreading and helpful comments.

References

1 von Suchodoletz W: Neue Studien zeigen: Training auditiver Funktionen für sprachgestörte Kinder ohne Nutzen. Forum Logop 2006;5:18-23.

-2 Mogford-Bevan K: Developmental language impairments with complex origins: learning from twins and multiple birth children. Folia Phoniatr Logop 2000;52:74-82.

3 American Speech-Language-Hearing Association (ASHA): (Central) Auditory Processing Disorders, Technical Report. Rockville, ASHA, 2005.

4 Gallagher T: Treatment research in speech, language and swallowing: lessons from child language disorders. Folia Phoniatr Logop 1998;50:165-182

5 Alonso-Búa B, Díaz F, Ferraces MJ: The contribution of AERPs (MMN and LDN) to studying temporal vs. linguistic processing deficits in children with reading difficulties. Int J Psychophysiol 2006;59:159-167. 
-6 Wright B, Lombardino L, King W: Deficits in auditory temporal and spectral resolution in language-impaired children. Nature 1997; 387:176-178.

7 Tallal P, Piercy M: Defects of non-verbal auditory perception in children with developmental aphasia. Nature 1973;241:468-469.

-8 Tallal P, Miller S, Fitch RH: Neurobiological basis of speech: a case for the preeminence of temporal processing. Ann NY Acad Sci 1993; 682:27-47.

-9 Rosen S: Auditory processing in dyslexia and specific language impairment: Is there a deficit? What is nature? Does it explain anything? J Phonet 2003;31:509-527.

10 Lauter J: Neuroimaging and the trimodal brain: applications for developmental communication neuroscience. Folia Phoniatr Logop 1998;50:118-145.

11 Jerger J, Musiek F: Report of the consensus conference on the diagnosis of auditory processing disorders in school-aged children. J Am Acad Audiol 2000;11:467-474.

-12 Ostroff J, Martin B, Boothroyd A: Cortical evoked responses to acoustic change within a syllable. Ear Hear 1998;19:290-297.

13 Harkrider A, Plyler P, Hedrick M: Effects of age and spectral shaping on perception and neural representation of stop consonant stimuli. Clin Neurophysiol 2005;116:2153-2164.

- 14 Nickisch A, Gross M, Schönweiler R, Uttenweiler V, am Zehnhoff-Dinnesen A, Berger R, Radü HJ, Ptok M: Auditory processing disorders: consensus statement by the German society of phoniatry and paedaudiology. HNO 2007;55:61-72.

15 Sharma M, Purdy SC, Newall P, Wheldall K, Beaman R, Dillon H: Electrophysiological and behavioural evidence of auditory processing deficits in children with reading disorder. Clin Neurophysiol 2006;117:11301144.

16 Cheour M, Leppänen P, Kraus N: Mismatch negativity (MMN) as a tool for investigating auditory discrimination and sensory memory in infants and children. Clin Neurophysiol 2000;111:4-16.

17 Holopainen I, Korpilahti P, Juottonen K: Abnormal frequency mismatch negativity in mentally retarded children and in children with developmental dysphasia. J Child Neurol 1998;13:178-183

$\checkmark 18$ Holopainen I, Korpilahti P, Juottonen K, Lang $\mathrm{H}$, Sillanpää M: Attenuated auditory event-related potentials (mismatch negativity) in children with developmental dysphasia. Neuropediatrics 1997;28:253-256

19 Jansson-Verkasalo E: Auditory Event-Related Potentials as Indices of Language Impairment in Children Born Preterm and with Asperger Syndrome. Oulu, Oulu University Press, 2003.

20 Korpilahti P: Auditory discrimination and memory functions in SLI: a comprehensive study with neurophysiological and behavioural methods. Scand J Logop Phoniatr 1995;20:131-139.

-21 Picton T, Alain C, Otten L: Mismatch negativity: different water in the same river. Audiol Neurootol 2000;5:111-139.
22 Schönweiler R, Wübbelt P, Tolloczko R: Classification of passive auditory event-related potentials using discriminant analysis and self-organizing feature maps. Audiol Neurootol 2000;5:69-82.

23 Näätänen R, Gaillard A, Mäntysalo S: Early selective-attention effect on evoked potential reinterpreted. Acta Psychol 1978;42:313-329.

24 Näätänen R: The role of attention in auditory information processing gas revealed by event-related potentials and other brain measures of cognitive function. Behav Brain Sci 1990;13:201-288.

25 Näätänen R, Pakarinen S, Rinne T: The mismatch negativity (MMN): towards the optimal paradigm. Clin Neurophysiol 2004;115: 140-144.

-26 Čeponiené R, Yaguchi K, Shestakova A: Sound complexity and 'speechness' effects on pre-attentive auditory discrimination in children. Int J Psychophysiol 2002;43:199-211.

27 Čeponiené R, Lepistö T, Soininen M, Aronen E, Alku P, Näätänen R: Event-related potentials associated with sound discrimination versus novelty detection in children. Psychophysiology 2004;41:130-141.

28 Korpilahti P, Lang H: Auditory ERP components and mismatch negativity in dysphasic children. Electroencephalogr Clin Neurophysiol 1994;91:256-264.

29 Lachmann T, Berti S, Kujala T, Schroger E: Diagnostic subgroups of developmental dyslexia have different deficits in neural processing of tones and phonemes. Int J Psychophysiol 2005;56:105-120.

30 Kujala T, Lovio R, Lepistö T, Laasonen M, Näätänen R: Evaluation of multi-attribute auditory discrimination in dyslexia with the mismatch negativity. Clin Neurophysiol 2006;117:885-893.

31 Baldeweg T, Richardson A, Watkins S, Foale C, Gruzelier J: Impaired auditory frequency discrimination in dyslexia detected with mismatch evoked potentials. Ann Neurol 1999;45:495-503.

32 Kraus N, McGee T, Zecker S, Nicol T, Koch D: Auditory neurophysiologic responses and discrimination deficits in children with learning problems. Science 1996;273:971973.

33 Meng X, Sai X, Wang C, Wang J, Sha S, Zhou $\mathrm{X}$ : Auditory and speech processing and reading development in Chinese school children behavioural and ERP evidence. Dyslexia 2005;11:292-310.

-34 Schulte-Körne G, Deimel W, Bartling J, Remschmidt $\mathrm{H}$ : The role of phonological awareness, speech perception, and auditory temporal processing for dyslexia. Eur Child Adolesc Psychiatry 1999;8:28-34.

35 Uwer R, Albrecht R, von Suchodoletz W: Automatic processing of tones and speech stimuli in children with specific language impairment. Dev Med Child Neurol 2002;44: 527-532.

36 Weiss R, Osterland J: Grundintelligenzskala 1, CFT1. Göttingen, Hogrefe, 1997.

37 Grimm H, Schöler H: Heidelberger Sprachentwicklungstest (HSET). Göttingen, Hogrefe, 1998.
38 Brunner M, Pfeiffer B, Troost J: Heidelberger Vorschulscreening zur auditiv-kinästhetischen Wahrnehmung und Sprachverarbeitung (HVS). Göttingen, Hogrefe, 2001.

-39 Brunner M, Pfeiffer B, Heinrich C, Pröschel U: Development and testing of the Heidelberg pre-school screening for auditory perception and speech processing (HVS). Folia Phoniatr Logop 2005;57:48-58.

40 Fox A: Psycholinguistische Analyse kindlicher Sprechstörungen (PLAKSS). Frankfurt am Main, Swets \& Zeitlinger, 2002.

41 Gabriel P, Chilla R: Göttinger Kindersprachverständnistest II. Wertingen, WESTRA Elektroakustik GmbH, 1976

42 Kummer P, Burger M, Schuster M, Rosanowski F, Eysholdt U, Hoppe U: Cortical auditory evoked potentials to acoustic changes in speech stimuli in children. Folia Phoniatr Logop 2007;59:273-280.

43 Jasper H: The ten-twenty electrode placement system of the international federation. Clin Neurophysiol 1958;10:371-375.

44 Burger M, Hoppe U, Kummer P, Lohscheller J, Eysholdt U, Döllinger M: Wavelet-based analysis of MMN responses in children. Biomed Tech (Berl) 2007;52:111-116.

45 McGee T, Kraus N, Nicole T: Is it really a mismatch negativity? An assessment of methods for determining response validity in individual subjects. Electroencephalogr Clin Neurophysiol 1997;104:359-368.

46 Lepistö T, Silokallio S, Nieminen-von Wendt T, Alku P, Näätänen R, Kujala T: Auditory perception and attention as reflected by the brain event-related potentials in children with the Asperger syndrome. Clin Neurophysiol 2006;117:2161-2171.

47 Korpilahti P, Lang H, Aaltonen O: Is there a late-latency mismatch negativity (MMN) component? Electroencephalogr Clin Neurophysiol 1995;95:96

48 Cheour M, Korpilahti P, Martynova O, Lang $\mathrm{AH}$ : Mismatch negativity and late discriminative negativity in investigating speech perception and learning in children and infants. Audiol Neurootol 2001;6:2-11.

-49 Shestakova A, Huotilainen M, Čeponiené R: Event-related potentials associated with second language learning in children. Clin Neurophysiol 2003;114:1507-1512.

50 Bishop D, McArthur G: Individual differences in auditory processing in specific language impairment: a follow-up study using event-related potentials and behavioural thresholds. Cortex 2005;41:327-341.

51 Čeponiené R, Rinne T, Näätänen R: Maturation of cortical sound processing as indexed by event-related potentials. Clin Neurophysiol 2002;113:870-882.

52 Gomes H, Dunn M, Ritter W, Kurtzberg D, Brattson A, Kreuzer J, Vaughan H: Spatiotemporal maturation of central and lateral N1 components to tones. Brain Res Dev Brain Res 2001;129:147-155.

53 Ponton C, Eggermont J, Kwong B, Don M: Maturation of human central auditory system activity: evidence from multi-channel evoked potentials. Clin Neurophysiol 2000; 111:220-236. 